\title{
An unusual cause of circulatory disorder due to a rare intermuscular hydatid cyst of cruris: A case report
}

\author{
Mehmet B Balioglu ${ }^{1}$ Mustafa Gok ${ }^{2}$, Hacer E Ozcan ${ }^{3}$, Okan Alpak $^{4}$ \\ 1. Department of Orthopaedics and Traumatology, Spine Surgery and Arthroplasty Clinic, Metin Sabanci Baltalimani Bone \\ Disease Education and Research Hospital, Istanbul, Turkey. 2. Department of Radiodiagnosis, Kafkas University, School of \\ Medicine, Kars, Turkey. 3. Department of Pathology, Kafkas University, School of Medicine, Kars, Turkey. 4. School of \\ Medicine, Sifa University, Gaziemir Hospital, Izmir, Turkey.
}

Correspondence: Mehmet B Balioglu. Address: Department of Orthopaedics and Traumatology, Spine Surgery and Arthroplasty Clinic, Metin Sabanci Baltalimani Bone Disease Education and Research Hospital, Rumeli Hisari Caddesi No: 62 Baltalimani, 34470, Istanbul, Turkey. E-mail: mbbalibey@gmail.com

Received: February 17, 2015

DOI : $10.5430 /$ crcp.v2n3p66
Accepted: April 23, 2015

URL: http://dx.doi.org/10.5430/crcp.v2n3p66

\section{Abstract}

Echinococcus granulosus with primary muscular involvement is difficult to diagnose and treat, as it is rarely observed. It may lead to an acute clinical presentation that is occasionally confused with peripheral circulatory disorder findings due to pressure impacts. A 48-year-old male patient has applied to our clinic with severe pain of the right cruris and circulatory disorder that is caused by the compressive effect of the extensive intermuscular cystic lesion surrounded by the septa between the gastrocnemius and soleus muscles. The cyst was carefully drained with needle aspiration, under the guidance of ultrasonography both for histopathological diagnosis and to reduce the compressive impact of the mass. Echinococcus granulosus was identified by histological and pathological inspection. Albendazole was administered daily $400 \mathrm{mg}(2 \times 1)$. After four weeks of treatment, the cyst, together with its capsule, was surgically removed and the patients recovered clinically. Prior to mass excision of the cyst, percutaneous needle aspiration increases the efficacy of medical and surgical treatment, and may be recommended in suitable cases in order to mitigate the risk of recurrence.

\section{Key words}

Echinococcus granulosus, Primer hydatid cyst, Muscle hydatidosis, Skeletal muscle, Circulatory disorder

\section{I ntroduction}

Hydatid disease is a parasitic ascarid (tenia, tapeworm) infection that involves the liver and lungs. However, primary skeletal muscle hydatid cyst (HC) involvement is rarely (0.5\%-4\%) observed, however due to its high recurrence risk, is considered as a serious public health problem in endemic regions ${ }^{[1-5]}$. Echinococcus granulosus (E. Granulosus), which can be considered as the reason for primary muscle involvement, is difficult to diagnose and treat as it is rarely observed ${ }^{[5]}$. In muscular HC treatment, en bloc resection and albendazole treatment are recommended as first line treatment ${ }^{[5]}$. The protocols for treating muscular $\mathrm{HC}$ by discharging the cyst with the percutaneous needle aspiration technique have been previously defined ${ }^{[6,7]}$. Our study aims at presenting the result of the treatment we applied and the percutaneous needle aspiration method in treating a primary $\mathrm{HC}$ case located between the gastrocnemius and soleus muscles in the cruris posterior, which caused circulation disorders in the patient's lower extremity. 


\section{Case presentation}

A 48-year-old male patient presented with symptoms of severe pain in the right lower extremity, popliteal zone and cruris posterior, edema, discoloration and peripheral circulatory disorder symptoms. The patient was initially examined for the diagnosis of hematoma, abscess or tumoral lesions with soft tissue involvement, which may result in compressive effects, or vascular pathology due to underlying circulatory disorders. During the examination of the lower extremity vascular structures and circulation with arterial-venous Doppler ultrasonography (DUSG), all arterial structures had triphasic normal arterial flow pattern, in venous structures there were no filling defect, flow loss or compressibility loss so there were no sign for deep vein thrombosis. A mass lesion in capsule form, without color coding on Doppler inspection and containing dense septation fields at approximately $180 \mathrm{~mm} \times 63 \mathrm{~mm} \times 36 \mathrm{~mm}$ dimensions, was observed at the posterior of the right cruris zone, under the medial head of the gastrocnemius muscle, extending from the medial of the lateral head proximal to the anterior of the gastrocnemius muscle's anterior, at the distal region, thus reaching under the skin (see Figure $1 \mathrm{a}, \mathrm{b})$.

Figure 1. The patient evaluated with USG longitudinal (a), transvers section (b). A mass lesion in capsule form was observed at the posterior of the right cruris zone, under the medial head of the gastrocnemius muscle. With MRI, in unenhanced series, PD, TSE and FS sagittal (c), T1 TSE sagittal (d), PD TSE FS transverse sections (e), post-contrast T1 TSE FS sagittal (f), transverse mass' proximal segment (g), distal segment images (h) were obtained.
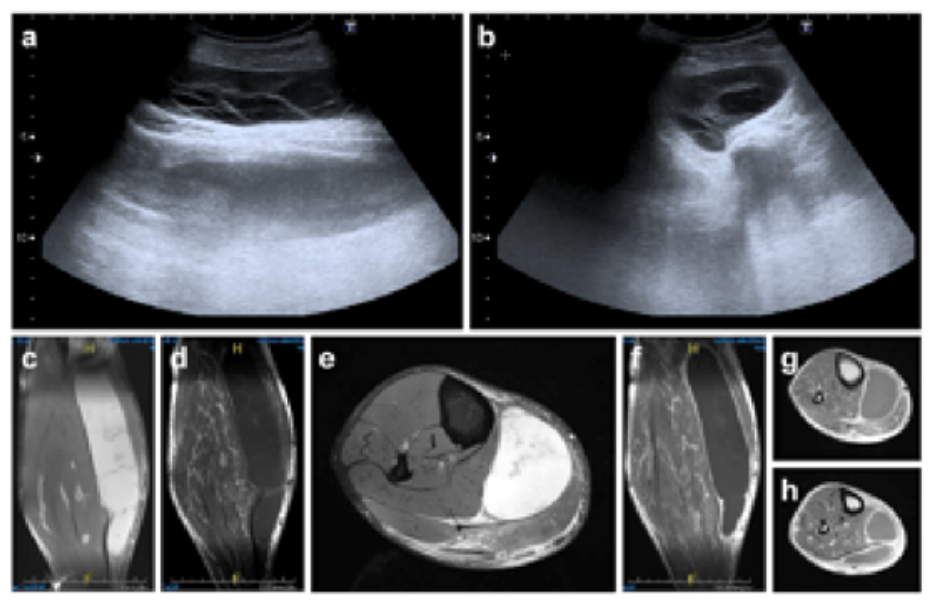

Direct graphy was performed but no significant calcification area was observed in the soft mass lesion on the right cruris, but an evident thickening was noted in the soft tissue at the posterior of cruris. The left cruris posterior tibial cortex-skin distance was measured as $8 \mathrm{~cm}$ at the thickest place, and in the right cruris it was measured as $11 \mathrm{~cm}$. Since the mass was located in the soft tissue magnetic resonance imaging (MRI) examination was carried out in the enhanced and unenhanced cruris zone. On MRI (Siemens Magnetom Essenza ${ }^{\mathrm{TM}}$, 1.5T), in unenhanced series, proton density (PD), turbo spin echo (TSE), fat suppressed (FS) coronal, sagittal and transverse sections, spin echo (T1 SE) coronal and turbo spin echo (T1 TSE) sagittal sections were obtained (see Figure 1 c-e).

A capsule was observed at the posterior of the right cruris zone, under the medial head of the gastrocnemius muscle in the proximal region, at the medial of the lateral head. It did not invade adjacent soft tissue and bone structures, and did not show any evident contrast from the septation structures, but showed an evident contrast from the wall in the enhanced series, which was hyperintense in the PD images, and hypointense in the T1 weighted images (WI). The capsule did not have any evident connection with the vascular structures. It contained dense septation fields of approximately $175 \mathrm{~mm} \times$ $60 \mathrm{~mm} \times 42 \mathrm{~mm}$, and extended under the skin by crossing the anterior of the gastrocnemius muscle at the distal region (see Figure $1 \mathrm{f}-\mathrm{h})$.

It was thought that the circulatory disorder at the lower extremity of the patient was caused by mass effect of the extensive intermuscular cystic lesion. In order to confirm the histopathological diagnosis and reduce the effect of the mass, an interferential interventional radiodiagnostic specialist accessed the mass with needle aspiration under the guidance of USG. In a single attempt, approximately $100 \mathrm{cc}$ liquid aspiration was performed (see Figure 2). Following the 
microbiological and histopathological examinations, the patient was diagnosed with HC (see Figure 3 a-c). Cranial, thoracic, lower-upper abdominal BT and lower-upper abdominal USG inspections were performed in the other organs of the patient to identify any other areas of HC. No other HC foci were identified, and the patient was diagnosed with "primary muscular hydatidosis".

Figure 2. In order to confirm the histopathological diagnosis and reduce the effect of the mass, an interferential interventional radiodiagnostic specialist accessed the mass with needle aspiration under the guidance of USG. In a single attempt, approximately $100 \mathrm{cc}$ liquid aspiration was performed.

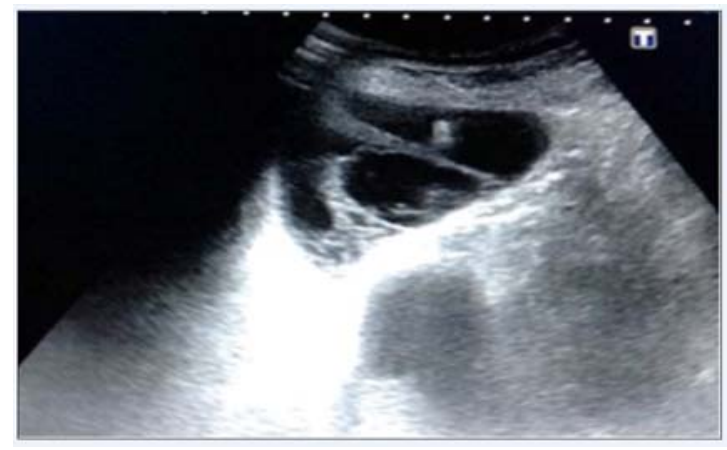

After USG guided, partial drainage and albendazole $(2 \times 400 \mathrm{mg}$ /day $)$ treatment began, an evident regression and relaxation was observed in his clinical profile, and his peripheral circulation returned to normal. The mass was removed with surgical mass excision and the control USG, which was carried out four weeks later, showed an evident regression in liquid collection. Longitudinal incision from cruris posteromedial was applied as the surgical technique. The entire capsule was excised in a controlled manner following the irrigation of the cyst's drainage and hypertonic saline infusion (see Figure 4 a-c). Post-operatively, 4 courses of Albendazole were administered for 4 weeks in 15 days intervals. On the 15 th post-op day, control USG showed slight liquid collection, and the control USG and MRI taken in the second month showed an evident regression in cutaneous-subcutaneous edema and in the operation field. During the clinical and MRI follow up eight months later, no finding compatible with $\mathrm{HC}$ was found (see Figure $5 \mathrm{a}, \mathrm{b}$ ). At the 24 months post-op follow-up, no clinical problems and recurrences were observed on the right cruris.

Figure 3. Scattered hooklets on aspirated fluid $($ MGG stain $\times$ 400) $($ MGG stain x1000) $(a, b)$. Turboid cyst aspirate fluid and inflammatory cells $($ MGG stain $\times 400)(c)$.
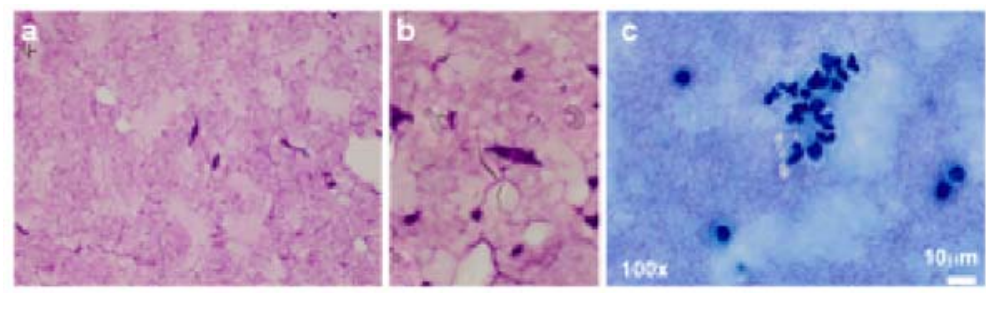

Figure 4. A longitudinal incision extending from right cruris posteromedial towards gastrocnemius muscle medial edge was made (a). After accessing the cyst capsule in the intermuscular field, the drainage was carefully accomplished, and the cyst capsule was excised completely proximal and distal to the intermuscular zone $(b, c)$.
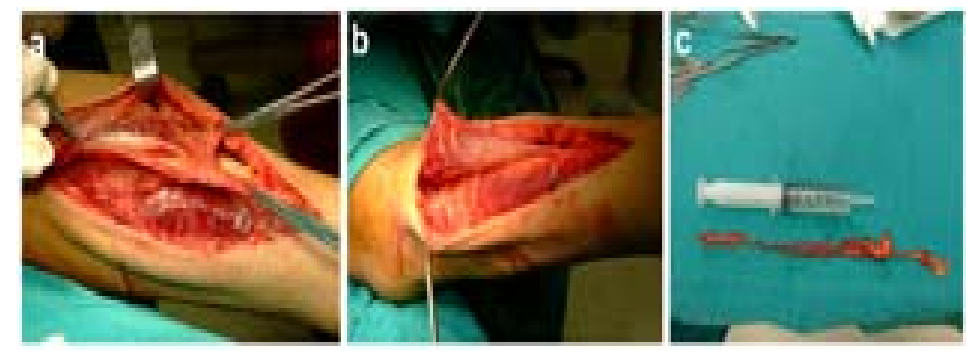

\section{Discussion}

Primary muscular hydatidosis, a zoonotic infection caused by Echinococcus granulosus larva, is mostly noted endemically in the regions were sheep breeding is performed ${ }^{[1-4]}$. The disease spreads by the entry of the larvae into the portal 
circulation after they penetrate into the intestinal mucosa. Because of the blood-filtering functions of the intestines, $75 \%$ of the larvae are transferred to the liver, $15 \%$ to lungs and the remaining to the other parts of the body, and musculo-skeletal involvement is observed only on $1 \%-4 \%$ of patients ${ }^{[1-4]}$. In particular, it the larva may spread to locations with high vascularity, such as the vertebrae, long bone epiphysis, ilia, skull and ribs ${ }^{[8-10]}$. The primary involvement of the skeletal muscle is rare due to the contractions on muscles and high lactic acid levels ${ }^{[11-13]}$. Muscle involvement has been observed in the muscles of the thoracic wall, pectoralis major, sartorius, biceps brachii, gracilis, tibialis anterior, supraspinatus, biceps femoris, gluteus maximus, gastrocnemius and paravertebral muscles ${ }^{[3,11,14-19]}$. Multiple cysts may develop and are observed in $20 \%$ of the infected individuals. Muscular HC can also be seen as general, isolated lesions without hepatic or pulmonary lesions ${ }^{[1-3,19]}$. Our case did not involve farming-animal husbandry in an endemic region for HC, and only the gastrocnemius and soleus muscles in the lower right extremity were involved. Serology may yield false negatives in almost half of primary muscular HC cases ${ }^{[3,19,20]}$. The result of the serologic test in our case was positive.

Figure 5. During the clinical and MRI follow up eight months later, no finding compatible with $\mathrm{HC}$ was found. The proton density turbo spin echo (TSE) fat suppressed sagittal (a), T1AG TSE coronal MRI results at 8 months post-op (b). No recurrences were identified.

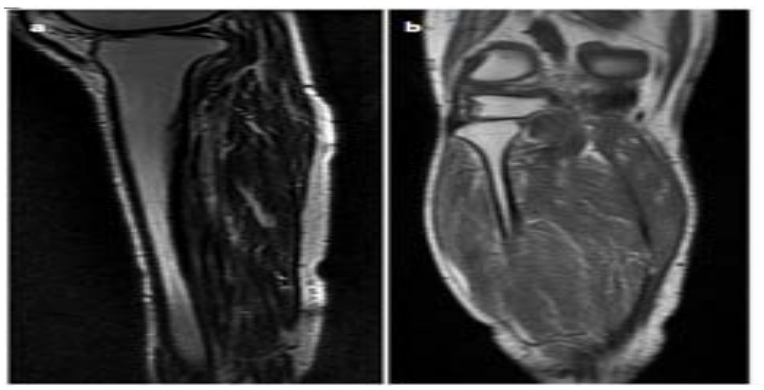

A detailed radiological assessment is required for correct diagnosis. Particularly in endemic zones, muscular HC should absolutely be considered in differential diagnosis ${ }^{[1,2,4]}$. HC may imitate tumors of the musculo-skeletal system, and it may grow as a slowly growing soft tissue mass and lead to misdiagnosis due to the lack of specific clinical and radiological findings. Because clinical indications also showed a slow progress in our case, the diagnosis could not be confirmed until the pain and circulation problem became evident. In $38 \%$ of patients, soft tissue calcification may also be seen in radiography ${ }^{[19]}$. Calcifications were not observed by radiography in our case. The use of USG is proposed in muscular HC diagnosis ${ }^{[7,19,21,22]}$. In USG, unilocular cysts, which contain daughter cysts, echogenic hydatid sand, a floating detached laminated membrane, and multivesicular cysts, may be observed ${ }^{[1,22]}$. MRI is beneficial in the differential diagnosis of other soft tissue cystic tumors, such as ganglion cyst, seroma, abscess and epidermoid inclusion cyst, and in malignancies located in the soft tissue ${ }^{[19]}$. Lesions may generally be observed with a general high signal density in T2-weighed images and low density in T1-weighed images, and low density rim in both $\mathrm{T} 1$ and $\mathrm{T} 2$-weighed images ${ }^{[11,13,22]}$. This rim finding is not specific for $\mathrm{HC}$, and it may also be observed in other lesions with a fibrosis capsule or a calcified rim ${ }^{[12]}$. Increases in peripheral reflection in pericystic vascularity have also been observed ${ }^{[12]}$. The presence of daughter cysts is very characteristic for $\mathrm{HC}$, although it has been reported that daughter cysts were not observed on $30 \%$ of cases ${ }^{[12]}$. Basarir et al. observed a cystic form with internal cyst in 3 of their 5 cases. In our case, we also applied MRI, in addition to USG, for a detailed examination of the cystic form ${ }^{[19]}$. We observed a cystic benign mass with capsular form, which was hyperintense on PD images and hypointense on T1AG images. There was evident contrast on the wall enhanced series, but no evident contrasting on septation structures. Additionally, there was no invasion in the adjacent soft tissue and bone structures.

As inappropriate incisional biopsy and marginal excision during treatment may reveal foreign proteins and scoleces the in the cyst and cause anaphylaxis and recurrence, they are contraindicated for $\mathrm{HC}{ }^{[11,12]}$. Chemotherapy on its own (such as with benzimidazole) is generally not sufficient for muscular HC. The treatment method requires complete and wide excision, similar to oncological procedures ${ }^{[4,23]}$. Total removal of the HC lesion may be difficult due to adjacent neurovascular structures. If performing a wide excision is difficult, then drainage should be done very carefully, and hypertonic saline irrigation should be applied concurrently ${ }^{[17]}$. Intra-operative irrigation with scoledial agents, such as hypertonic 
saline, prevents recurrence caused by inoculation of scoleces during excision ${ }^{[11]}$. The bleeding of the cyst content and the dissemination of live scoleces increase the recurrence ratio ${ }^{[10]}$. Başarır et al., applied wide excision in 3 cases, and marginal excision and hypertonic saline irrigation in 2 cases, due to the proximity of the lesion to the vascular tissues. Almost all patients subsequently recovered, and recurrence was only observed in one patient ${ }^{[19]}$. Complementary pharmacological treatment is recommended to last for 3 to 4 weeks with 14-day intervals ${ }^{[24,25]}$. For muscular HC treatment, en bloc resection is recommended before the rupture and spread of daughter cysts ${ }^{[3,5]}$. The puncture-aspiration-injectionre-aspiration (PAIR) technique, which was developed as an alternative to surgical excision of liver HC, involves the removal of the contents of $\mathrm{HC}$ by means of USG, injection of scolecidal agents, such as $95 \%$ ethanol, and re-aspiration of the cyst contents ${ }^{[26,27]}$. The use of percutaneous drainage with or without re-aspiration (PAIR) in HC treatment was indicated, in particular, for cases which are inoperable or for patients who rejected surgery ${ }^{[6,7,28,29]}$. Albendazole treatment is recommended to prevent contamination by needle aspiration ${ }^{[6]}$.

In our case, an interventional radiology specialist carried out needle aspiration, initially accompanied by USG. This was aimed collecting material for pathological and microbiological evaluation, and to reduce the effect of circulatory disorders caused by the pressure of the cystic mass. As demonstrated in our case, the proximity of $\mathrm{HC}$ to the skin and the application of needle aspiration by an experienced radiologist under USG control could minimize the risk of contamination and the development of anaphylaxis. The application of wide surgical excision following a 4-week follow-up with additional albendazole treatment may eliminate the risk of recurrence and anaphylaxis ${ }^{[30]}$. It may also enable histopathological inspection for earlier diagnosis.

The correct diagnosis and treatment of $\mathrm{HC}$ caused by primary muscular Echinococcus granulosus is difficult, as it is rarely observed. Its differential diagnosis is generally made based on abscess present in soft tissue, hematoma, and other cystic lesions or malignant tumors. As observed in our case, it may create circulatory disorders, such as compartment syndrome or deep vein thrombosis, in neglected patients. In conveniently located lesions, the early and quick diagnosis of the pathology may be possible with carefully implemented needle aspiration accompanied by USG. Complications may also be avoided as the reduced compression enables better circulation in the extremities. As such, the probability of HC should also be considered in differential diagnosis, especially in cases accompanied by painful circulatory disorders observed in the extremities in endemic regions.

\section{References}

[1] Ammari FF, Khasawneh Z, Salem MK, et al. Hydatid disease of the musculoskeletal system. Surgery. 1998; 124(5): 934-7. PMID: 9823412. http://dx.doi.org/10.1016/S0039-6060(98)70022-4

[2] Merkle EM, Schulte M, Vogel J, et al. Musculoskeletal involvement in cystic echinococcosis: report of eight cases and review of the literature. AJR Am J Roentgenol. 1997; 168(6): 1531-4. PMID: 9168719. http://dx.doi.org/10.2214/ajr.168.6.9168719

[3] Garcia-Alvarez F, Torcal J, Salinas JC, et al. Musculoskeletal hydatid disease: a report of 13 cases. Acta Orthop Scand. 2002; 73(2): 227-31. PMID: 12079024. http://dx.doi.org/10.1080/000164702753671858

[4] Orhan Z, Kara H, Tuzuner T, et al. Primary subcutaneous cyst hydatic disease in proximal thigh: an unusual localisation: a case report. BMC Musculoskelet Disord. 2003; 4: 25. http://dx.doi.org/10.1186/1471-2474-4-25

[5] Arazi M, Erikoglu M, Odev K, et al. Primary echinococcus infestation of the bone and muscles. Clin Orthop Relat Res. 2005; 432: 234-41. PMID: 15738827. http://dx.doi.org/10.1097/01.blo.0000149816.86222.2d

[6] Bilgic S, Kose O, Sehirlioglu A, et al. Primary paraspinal hydatid cyst treated with puncture, aspiration, injection and re-aspiration (PAIR) technique: a case report. Eur Spine J. 2009; 18(Suppl 2): S165-7. http://dx.doi.org/10.1007/s00586-008-0737-3

[7] Ormeci N, Idilman R, Akyar S, et al. Hydatid cysts in muscle: a modified percutaneous treatment approach. Int J Infect Dis. 2007; 11(3): 204-8. http://dx.doi.org/10.1016/j.ijid.2005.10.015

[8] Martin J, Marco V, Zidan A, et al. Hydatid disease of the soft tissues of the lower limb: findings in three cases. Skeletal Radiol. 1993; 22(7): 511-4. PMID: 8272887. http://dx.doi.org/10.1007/BF00209098

[9] Alldred AJ, Nisbet NW. Hydatid disease of bone in Australasia. J Bone Joint Surg Br. 1964; 46: 260-7. PMID: 14167635.

[10] Papanikolaou A, Antoniou N, Pavlakis D, et al. Hydatid disease of the tarsal bones. A case report. J Foot Ankle Surg. 2005; 44(5): 396-400. http://dx.doi.org/10.1053/j.jfas.2005.07.004 
[11] Duncan GJ, Tooke SM. Echinococcus infestation of the biceps brachii. A case report. Clin Orthop Relat Res. 1990; 261: 247-50. http://dx.doi.org/10.1097/00003086-199012000-00029

[12] Guthrie JA, Lawton JO, Chalmers AG. Case report: the MR appearances of primary intramuscular hydatid disease. Clin Radiol. 1996; 51(5): 377-9. http://dx.doi.org/10.1016/S0009-9260(96)80122-X

[13] Garcia-Diez AI, Ros Mendoza LH, Villacampa VM, et al. MRI evaluation of soft tissue hydatid disease. Eur Radiol. 2000; 10(3): 462-6. http://dx.doi.org/10.1007/s003300050077

[14] Bayram M, Sirikci A. Hydatic cyst located intermuscular area of the forearm: MR imaging findings. Eur J Radiol. 2000; 36(3): 130-2. PMID: 11091011. http://dx.doi.org/10.1016/S0720-048X(00)00188-1

[15] Rask MR, Lattig GJ. Primary intramuscular hydatidosis of the sartorius. Report of a case. J Bone Joint Surg Am. 1970; 52(3): 582-4. PMID: 5425654.

[16] Tarhan NC, Tuncay IC, Barutcu O, et al. Unusual presentation of an infected primary hydatid cyst of biceps femoris muscle. Skeletal Radiol. 2002; 31(10): 608-11. http://dx.doi.org/10.1007/s00256-002-0524-x

[17] Tatari H, Baran O, Sanlidag T, et al. Primary intramuscular hydatidosis of supraspinatus muscle. Arch Orthop Trauma Surg. 2001; 121(1-2): 93-4. PMID: 11195130. http://dx.doi.org/10.1007/PL00013775

[18] Durakbasa MO, Kose O, Islam NC, et al. A primary hydatid cyst of the gracilis: a case report. J Orthop Surg (Hong Kong). 2007; 15(1): 118-20.

[19] Basarir K, Saglik Y, Yildiz Y, et al. Primary muscular hydatidosis mimicking soft tissue tumour: a report of five cases. J Orthop Surg (Hong Kong). 2008; 16(3): 368-72.

[20] Prousalidis J, Tzardinoglou K, Sgouradis L, et al. Uncommon sites of hydatid disease. World J Surg. 1998 Jan; $22(1)$ : 17-22. PMID: 9465756. http://dx.doi.org/10.1007/s002689900343

[21] Memis A, Arkun R, Bilgen I, et al. Primary soft tissue hydatid disease: report of two cases with MRI characteristics. Eur Radiol. 1999; 9(6): 1101-3. http://dx.doi.org/10.1007/s003300050798

[22] Koc Z, Agildere AM, Yalcin O, et al. Primary hydatid cyst in the anterior thigh: sonographic findings. J Clin Ultrasound. 2004; 32(7): 358-60. http://dx.doi.org/10.1002/jcu.20044

[23] Zlitni M, Ezzaouia K, Lebib H, et al. Hydatid cyst of bone: diagnosis and treatment. World J Surg. 2001; 25(1): 75-82. PMID: 11213159. http://dx.doi.org/10.1007/s002680020010

[24] Natarajan MV, Kumar AK, Sivaseelam A, et al. Using a custom mega prosthesis to treat hydatidosis of bone: a report of 3 cases. J Orthop Surg (Hong Kong). 2002; 10(2): 203-5.

[25] Kalinova K, Proichev V, Stefanova P, et al. Hydatid bone disease: a case report and review of the literature. J Orthop Surg (Hong Kong). 2005; 13(3): 323-5.

[26] Mueller PR, Dawson SL, Ferrucci JT Jr, et al. Hepatic echinococcal cyst: successful percutaneous drainage. Radiology. 1985; 155(3): 627-8. http://dx.doi.org/10.1148/radiology.155.3.3890001

[27] Smego RA Jr, Bhatti S, Khaliq AA, et al. Percutaneous aspiration-injection-reaspiration drainage plus albendazole or mebendazole for hepatic cystic echinococcosis: a meta-analysis. Clin Infect Dis. 2003; 37(8): 1073-83. http://dx.doi.org/10.1086/378275

[28] Yucesoy C, Ozturk E, Hekimoglu B. Radiologic findings and percutaneous treatment of a rare giant soft tissue hydatid cyst. JBR-BTR. 2013; 96(5): 286-9. PMID: 24479288.

[29] Melis M, Marongiu L, Scintu F, et al. Primary hydatid cysts of psoas muscle. ANZ J Surg. 2002; 72(6): 443-5. http://dx.doi.org/10.1046/j.1445-2197.2002.02420.x

[30] Alimehmeti R, Seferi A, Rroji A, et al. Saphenous neuropathy due to large hydatid cyst within long adductor muscle: case report and literature review. J Infect Dev Ctries. 2012; 6(6): 531-5. PMID: 22706197. http://dx.doi.org/10.3855/jidc.1766 